\title{
TWO COMPLEX ADAPTIVE SYSTEMS IN HUMAN DEVELOPMENT: FURTHER STUDIES OF DENTAL AND FINGERPRINT PARAMETERS
}

\author{
R.J.O. TADURAN ${ }^{1}$, S. RANJITKAR ${ }^{1}$, T. HUGHES ${ }^{1}$, G. TOWNSEND ${ }^{1}$ \& A.H. BROOK ${ }^{1,2}$ \\ ${ }^{1}$ Craniofacial Biology Research Group, Adelaide Dental School, University of Adelaide, Australia. \\ ${ }^{2}$ School of Dentistry, Queen Mary University, London, UK.
}

\begin{abstract}
This paper reports further results and an extension of the study presented at Complex Systems 2016. Human teeth and fingerprints both arise from genetic/epigenetic/environmental interactions and have embryological pathways with epithelial-mesenchymal interactions. The aims of this study were to determine the nature and extent of sexual dimorphism in teeth and fingerprints of twins at two different ages and to explore whether both systems display the features of complex adaptive systems. Buccolingual (BL) measurements from both primary and permanent teeth and ridge breadth (RB) measurements from fingerprints of the same set of Australian twins ( 28 males and 31 females aged 8 to 10 years, and aged 13 to 16 years, respectively) were collected and analysed. Sexual dimorphism was observed in both the primary and permanent dentitions, with the latter showing greater differences than the former. There was no observed sexual dimorphism in the fingerprints at 8 to 10 years. However, a few fingers (left index, left ring, and right middle) at 13 to 16 -years exhibited significant differences, suggesting that friction ridges expand over time. It is concluded that both the dentition and dermatoglyphics display sexual dimorphism and characteristics of complex adaptive systems.
\end{abstract}

Keywords: buccolingual, complex adaptive system, dentition, dermatoglyphics, fingerprints, human development, ridge breadth, sexual dimorphism, tooth size

\section{INTRODUCTION}

Sexual dimorphism is the difference between sexes of the same biological species in phenotype or appearance. Some researchers have proposed that sexual differences are regulated by sex chromosomes $[1,2]$, but there are some who have suggested that hormonal influences are also important $[3,4]$. Sexual dimorphism in human dentition and dermatoglyphs have been studied separately, and results are fairly consistent: males have larger tooth crown diameters than females [5, 6], sexual dimorphism is greater in permanent than in primary teeth $[6,7]$ and adult males have fewer finger ridges than females $[8,9]$.

Human development is a complex adaptive process that is influenced by genetic, epigenetic and environmental factors [10]. Genes interact with epigenetic and environmental elements and create complex networks within cells, and from this process the higher level tissues are formed. During embryonic growth, patterning, or the establishment of groups of cells in the proper relationship to each other and to surrounding tissues, occurs. Patterning is a longitudinal event that eventually leads to differentiation of cells to assume specialised functions and shapes.

The development of the human dentition and dermatoglyphs has similar embryological origin from epithelial-mesenchymal interactions [11]. Primary teeth commence development around 4 to 6 weeks in utero [10], while ridged skin on the fingers starts to form around 10 to 16 weeks in utero [12]. Once the patterns have been stabilised, their unique and persistent morphology makes them valuable models in studying sexual dimorphism. Only one study has explored possible correlations between the human dentition and dermatoglyphs in sub-adult Australian twins, and sexual dimorphism was observed in both primary and permanent teeth 
but not in fingerprints [13]. This study aimed to determine the nature and extent of sexual dimorphism in teeth and fingerprints of twins and explore whether both systems display the features of complex adaptive systems.

\section{MATERIALS AND METHODS}

Twin samples were acquired from the ongoing longitudinal research of the Craniofacial Biology Research Group in the Adelaide Dental School at the University of Adelaide [14], which is one of the four most extensive studies of its type in the world [15]. Serial casts of primary and permanent teeth, and rolled ink fingerprints of individuals aged 8 to 10 years and 13 to 16 years from a single cohort of monozygotic and dizygotic Australian twins (28 males and 31 females) were gathered and analysed. Dental casts showing wear, caries, or restorations and ten-prints with smudged ink and scarred patterns in any of the fingerprints were excluded.

Buccolingual crown diameter (BL) was measured as the breadth or distance between the buccal/labial and lingual surfaces of the crown $[16,17]$ by using a 2D imaging system. Using an adjustable stage, dental casts were orientated to obtain the correct plane or angle before obtaining images and calibrated Image J [18] software was used to digitise landmarks (Fig. 1). Measurements were obtained for central incisors (I1), lateral incisors (I2), canines (C), first molars (M1) and second molars (M2) of primary and permanent teeth.

Ridge breadth (RB) was determined by measuring the distance of 10 parallel ridges with no obstruction such as scars or white creases and/or interfering minutiae such as bifurcations, ridge endings, and short ridges. Measurements began and ended with valleys, or the spaces before the first ridge and after the tenth ridge (Fig. 2). This method is independent and not influenced by fingerprint pattern type and finger area [19].

Data were statistically analysed using XLSTAT statistical software. Descriptive statistics including means, standard deviations (SD) and coefficients of variation (CV) were computed

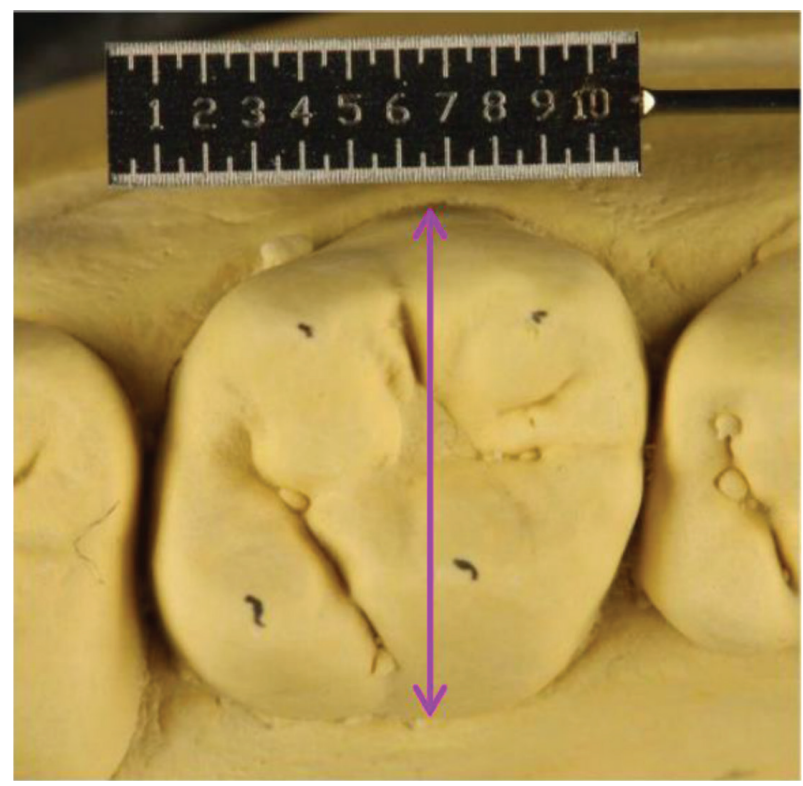

Figure 1: Buccolingual (BL) measurement of a permanent upper first molar from the occlusal view. 


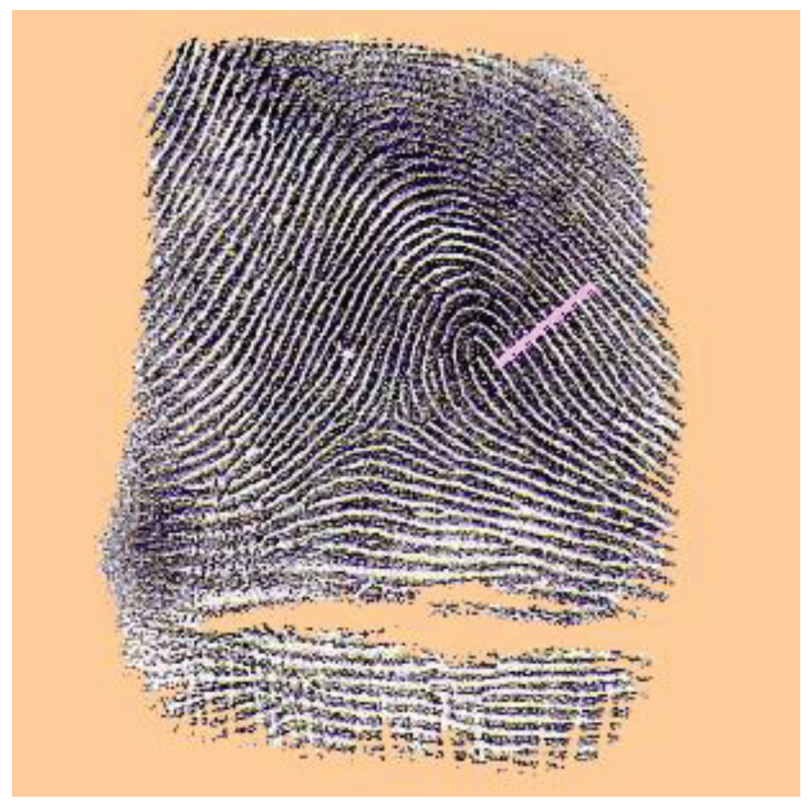

Figure 2: Sample of Ridge Breadth (RB) measurement.

for BL and RB variables. Differences between sexes and sides were calculated using Student's unpaired t-test. RB differences between age groups were compared with paired t-tests, and differences among fingers were examined with analysis of variance (ANOVA). Pearson's correlation coefficient was calculated to examine the strength of associations between the variables.

\section{RESULTS}

$\mathrm{BL}$ and $\mathrm{RB}$ measurements were found to be normally distributed, and results of intra- and inter-operator repeatability tests determined that errors in measurements were negligible and not likely to bias the results. Shown in Table 1 are the mean values, SD and CV of buccolingual (BL) measurements of primary and permanent teeth.

Highlighted in yellow are the sexually dimorphic dental measurements, where mean values are different between sexes at $\mathrm{p}<0.05$. Mean values of BL crown sizes of males were consistently greater compared to females in all types of teeth. Permanent dentitions showed greater sexual dimorphism compared to primary dentitions. There were no left-right differences observed in BL measurements of all primary and permanent teeth.

Shown in Table 2 are the mean values, SD and CV of ridge breadth (RB) of fingerprints of 8 to 10 year-old cohort and 13 to 16 year-old cohort.

All mean values of RB were statistically different to each other at $p<0.05$. Highlighted in blue are the RB means that were found to be statistically different on both sides. More leftright differences were observed in the younger ( 8 to 10 years old) cohort. Most fingers were asymmetric in both sexes, except for the index fingers and thumbs in males and index fingers in females. It was observed that fingers on the right side consistently have greater RB, which indicates thicker finger ridges. 
Table 1: Descriptive statistics for buccolingual (BL) measurements of primary and permanent teeth of Australian twins.

\begin{tabular}{|c|c|c|c|c|c|c|c|c|c|c|c|c|c|c|c|c|}
\hline & \multicolumn{8}{|c|}{ Males } & \multicolumn{8}{|c|}{ Females } \\
\hline & \multicolumn{3}{|c|}{ Right } & \multicolumn{5}{|c|}{ Left } & \multicolumn{3}{|c|}{ Right } & \multicolumn{5}{|c|}{ Left } \\
\hline & $\mathbf{n}$ & Mean & SD & $\begin{array}{l}\text { CV } \\
(\%)\end{array}$ & $\mathbf{n}$ & Mean & SD & $\begin{array}{l}\text { CV } \\
(\%)\end{array}$ & $\mathbf{n}$ & Mean & SD & $\begin{array}{l}\text { CV } \\
(\%)\end{array}$ & $\mathbf{n}$ & Mean & SD & $\begin{array}{l}\text { CV } \\
(\%)\end{array}$ \\
\hline \multicolumn{17}{|c|}{$\begin{array}{l}\text { Primary } \\
\text { Maxillary }\end{array}$} \\
\hline i1 & 28 & 5.07 & 0.33 & 6.44 & 28 & 5.12 & 0.33 & 6.38 & 31 & 4.92 & 0.34 & 6.97 & 31 & 4.96 & 0.36 & 7.25 \\
\hline c & 28 & 6.20 & 0.42 & 6.81 & 28 & 6.18 & 0.42 & 6.87 & 31 & 6.10 & 0.39 & 6.41 & 31 & 6.08 & 0.38 & 6.23 \\
\hline m1 & 28 & 8.79 & 0.43 & 4.88 & 28 & 8.76 & 0.42 & 4.77 & 31 & 8.55 & 0.34 & 3.96 & $31 \varepsilon$ & 8.54 & 0.34 & 4.01 \\
\hline $\mathrm{m} 2$ & 28 & 10.00 & 0.48 & 4.76 & 28 & 9.96 & 0.43 & 4.37 & 31 & 9.68 & 0.40 & 4.12 & 31 & 9.64 & 0.39 & 4.02 \\
\hline \multicolumn{17}{|c|}{ Mandibular } \\
\hline i1 & 28 & 3.88 & 0.30 & 7.62 & 28 & 3.83 & 0.25 & 6.40 & 31 & 3.72 & 0.27 & 7.30 & 31 & 3.71 & 0.24 & 6.58 \\
\hline i2 & 28 & 4.40 & 0.33 & 7.48 & 28 & 4.38 & 0.31 & 6.99 & 31 & 4.28 & 0.29 & 6.71 & 31 & 4.29 & 0.28 & 6.60 \\
\hline c & 28 & 5.65 & 0.36 & 6.40 & 28 & 5.65 & 0.36 & 6.32 & 31 & 5.58 & 0.38 & 6.90 & 315 & 5.58 & 0.35 & 6.29 \\
\hline m1 & 28 & 7.09 & 0.38 & 5.31 & 28 & 7.17 & 0.37 & 5.16 & 31 & 6.86 & 0.40 & 5.77 & 31 & 6.94 & 0.37 & 5.29 \\
\hline m2 & 28 & 8.72 & 0.38 & 4.36 & 28 & 8.72 & 0.38 & 4.35 & 31 & 8.38 & 0.40 & 4.82 & 31 & 8.41 & 0.37 & 4.36 \\
\hline \multirow{2}{*}{\multicolumn{17}{|c|}{$\begin{array}{l}\text { Permanent } \\
\text { Maxillary }\end{array}$}} \\
\hline & & & & & & & & & & & & & & & & \\
\hline I1 & 28 & 7.27 & 0.56 & 7.69 & 28 & 7.29 & 0.55 & 7.55 & 31 & 7.04 & 0.55 & 7.75 & 31 & 7.04 & 0.56 & 7.93 \\
\hline $\mathrm{C}$ & 28 & 8.32 & 0.56 & 6.73 & 28 & 8.41 & 0.61 & 7.28 & 31 & 7.91 & 0.54 & 6.81 & 31 & 7.97 & 0.56 & 6.96 \\
\hline M1 & 28 & 11.79 & 0.56 & 4.79 & 28 & 11.73 & 0.54 & 4.60 & 31 & 11.22 & 0.53 & 4.75 & 31 & 11.16 & 0.50 & 4.48 \\
\hline M2 & 28 & 11.95 & 0.70 & 5.88 & 28 & 12.07 & 0.84 & 7.00 & 31 & 11.18 & 0.69 & 6.14 & 31 & 11.07 & 0.61 & 5.48 \\
\hline \multicolumn{17}{|c|}{ Mandibular } \\
\hline I1 & 28 & 6.19 & 0.46 & 7.41 & 28 & 6.13 & 0.51 & 8.34 & 31 & 5.93 & 0.46 & 7.74 & 31 & 5.97 & 0.43 & 7.23 \\
\hline I2 & 28 & 6.47 & 0.53 & 8.23 & 28 & 6.41 & 0.55 & 8.51 & 31 & 6.25 & 0.53 & 8.41 & 31 & 6.28 & 0.47 & 7.47 \\
\hline C & 28 & 7.66 & 0.65 & 8.50 & 28 & 7.66 & 0.65 & 8.45 & 31 & 7.20 & 0.48 & 6.64 & 31 & 7.29 & 0.57 & 7.77 \\
\hline M1 & 28 & 10.54 & 0.47 & 4.48 & 28 & 10.56 & 0.50 & 4.70 & 31 & 9.99 & 0.48 & 4.78 & 31 & 10.07 & 0.48 & 4.77 \\
\hline M2 & 28 & 10.70 & 0.58 & 5.39 & 28 & 10.64 & 0.61 & 5.70 & 31 & 10.01 & 0.61 & 6.12 & 31 & 10.07 & 0.57 & 5.68 \\
\hline
\end{tabular}

Highlighted in yellow are the sexually dimorphic RB measurements, where mean values are different between sexes at $\mathrm{p}<0.05$. Left index, right middle and left ring fingers were observed to exhibit male-female differences in the older cohort (13 to 16 years old), with greater mean values for RB in males, which indicates thicker friction ridges. Based on paired t-test, all mean values of RB are different between age groups at $\mathrm{p}<0.05$, with the older cohort having greater RB values compared to the younger group. 
Table 2: Descriptive statistics for ridge breadth (RB) of fingerprints of Australian twins.

\begin{tabular}{|c|c|c|c|c|c|c|c|c|c|c|c|c|c|}
\hline & \multicolumn{7}{|c|}{ Males } & \multicolumn{6}{|c|}{ Females } \\
\hline & \multicolumn{3}{|c|}{ Right } & \multicolumn{4}{|c|}{ Left } & \multicolumn{3}{|c|}{ Right } & \multicolumn{3}{|c|}{ Left } \\
\hline & n Mear & n SD & $\begin{array}{l}\text { CV } \\
(\%)\end{array}$ & $\mathbf{n}$ & Mean & n SD & $\begin{array}{l}\text { CV } \\
(\%)\end{array}$ & n Mean & SD & $\begin{array}{l}\text { CV } \\
(\%)\end{array}$ & n Mean & n SD & $\begin{array}{l}\text { CV } \\
(\%)\end{array}$ \\
\hline \multicolumn{14}{|c|}{ 8-10 years old } \\
\hline Thumb & 284.24 & 0.54 & 12.66 & 28 & 4.21 & 0.57 & 13.59 & 314.32 & 0.58 & 13.39 & 314.07 & 0.46 & 11.24 \\
\hline Index & 283.98 & 0.45 & 11.21 & 28 & 3.97 & 0.60 & 15.19 & 313.98 & 0.46 & 11.58 & 313.94 & 0.48 & 12.22 \\
\hline Middle & 283.92 & 0.51 & 13.07 & 28 & 3.76 & 0.49 & 13.15 & 313.93 & 0.50 & 12.77 & 313.69 & 0.50 & 13.65 \\
\hline Ring & 283.83 & 0.54 & 14.09 & 28 & 3.49 & 0.45 & 12.98 & 313.83 & 0.44 & 11.46 & 313.46 & 0.45 & 13.16 \\
\hline Little & 283.80 & 0.54 & 14.23 & 28 & 3.61 & 0.48 & 13.37 & 313.82 & 0.47 & 12.24 & 313.67 & 0.42 & 11.39 \\
\hline \multicolumn{14}{|c|}{ 13-16 years old } \\
\hline Thumb & 284.69 & 0.54 & 11.58 & 28 & 4.68 & 0.55 & 11.79 & 314.61 & 0.59 & 12.90 & 314.55 & 0.52 & 11.39 \\
\hline Index & 284.40 & 0.55 & 12.60 & 28 & 4.62 & 0.56 & 12.19 & 314.36 & 0.65 & 15.00 & 314.30 & 0.53 & 12.29 \\
\hline Middle & 284.29 & 0.60 & 13.99 & 28 & 4.05 & 0.41 & 10.07 & 314.03 & 0.39 & 9.72 & 313.89 & 0.50 & 12.77 \\
\hline Ring & 284.12 & 0.52 & 12.57 & 28 & 3.88 & 0.45 & 11.72 & 313.94 & 0.51 & 12.87 & 313.64 & 0.43 & 11.72 \\
\hline Little & 284.16 & 0.53 & 12.64 & 28 & 4.06 & 0.51 & 12.48 & 314.09 & 0.38 & 9.28 & 313.95 & 0.40 & 10.22 \\
\hline
\end{tabular}

Pearson's coefficients (r) between teeth and fingerprints are presented in Table 3. Highlighted in yellow are the statistically significant correlations between dental characteristic, BL, and dermatoglyphic trait, $\mathrm{RB}$ at $\mathrm{p}<0.05$. In general, the correlations between teeth and fingerprints are statistically significant but low in magnitude.

Correlation coefficients were calculated within groups of dental and dermatoglyphic variables with significance set at $\mathrm{p}<0.05$. All BL measurements taken from different tooth types were positively correlated to each other in the primary teeth (0.32 to 0.92 ). Meanwhile, only some BL diameters (128 of 306 in males, 226 of 306 in females) were positively correlated to each other in the permanent teeth ( 0.36 to 0.94 ), and more significant values were observed in females than males. On the other hand, only some RB measurements from different fingers were positively correlated to each other (90 of 90 in young males and 83 of 90 in young females, 64 of 90 in old males and 40 of 90 in old females), with more significant values in males, and all values are significant in the young cohort males. Greater $r$ values were observed in $\mathrm{RB}$ at an older age ( 0.39 to 0.76$)$ compared to the younger age (0.21 to 0.67$)$.

Table 3: Pearson correlation coefficients of BL (buccolingual width) and RB (ridge breadth).

\begin{tabular}{llccc}
\hline & \multicolumn{2}{c}{ Primary } & \multicolumn{2}{c}{ Permanent } \\
\cline { 2 - 5 } Ridge Breadth & Maxillary & Mandibular & Maxillary & Mandibular \\
\hline Males & 0.28 & 0.30 & 0.25 & 0.35 \\
Females & 0.28 & 0.29 & 0.24 & 0.37 \\
\hline
\end{tabular}




\section{DISCUSSION}

The degree and patterning of sexual dimorphism in the dentition varies according to tooth type. Our observation of the permanent dentition showing more pronounced sexual dimorphism than the primary dentition agrees with previous findings $[4,13]$. The permanent molars displayed the largest sexual dimorphism in BL measurements, similar to previous studies [20, 21]. It has been suggested that dental development might occur under relatively high levels of testosterone influence [4], and this could explain the differences in sexual dimorphism between primary and permanent teeth of same individuals.

The degree and patterning of sexual dimorphism in the dermatoglyphs varies according to finger type and side. In this study, there was no observed sexual dimorphism at the age of 8 to 10 years, while fingerprints at 13 to 16 years of age displayed sexual dimorphism in the left index and ring fingers, and right middle finger. Our results are consistent with our previous study and support the idea that friction ridges expand as individuals grow and develop, probably more in males than females [13]. Sexual dimorphism in dermatoglyphic development seems to be initiated during puberty, when a testosterone surge occurs in males [22].

In normal male development, three surges of testosterone occur: the first surge happens at around the 7th to 9th week of pregnancy, and the testosterone level is highest around the 14th week following testicular differentiation [23, 24]; the second surge initiates after birth because of the reduction of oestrogen produced by the placenta [22]; and the third surge occurs during puberty. Meanwhile, primary teeth begin to form at around 4 to 6 weeks in utero [11] until around one year after birth. Permanent teeth commence development 14 weeks in utero and around 14 years of age [25]. On the other hand, primary ridges start to form at around 10 to 16 weeks and end on the 17th week, then secondary ridges develop until the 24th week in utero [12]. Our results are consistent with our previous study [13] and further support the idea that the first two testosterone surges have a critical role in the sexual dimorphism of both the primary and permanent teeth, while the third testosterone surge strongly influences the sexual dimorphism of fingerprints.

The human body is a complex adaptive system, and human development is a complex adaptive process [10]. This research has shown that both teeth and fingerprints are interconnected, yet they still have a degree of autonomy. They share a similar embryological origin and epithelialmesenchymal interactions [11], yet they develop and interact with epigenetic and environmental factors differently. The interactions may be unpredictable, with no central control, but they are not random, as regularities and patterns emerge to find the best fit with the environment.

This research furthers the investigation on the complex mechanisms and interactions occurring during dental, dermatoglyphic and general development with buccolingual (BL) measurements of the teeth and ridge breadth $(\mathrm{RB})$ measurements of the fingerprints. It is our second attempt to study both human dental and dermatoglyphic traits. Most studies have been conducted on the human dentition and dermatoglyphs separately, and no effort has been made to explore possible correlations between the two.

\section{ACKNOWLEDGEMENTS}

The authors wish to thank The Australian Dental Research Foundation (ADRF), the NHMRC of Australia, Australian Twin Registry and Australian Multiple Birth Association. 


\section{REFERENCES}

[1] Guatelli-Steinberg, D., Sciulli, P.W. \& Betsinger, T.K., Dental crown size and sex hormone concentrations: another look at the development of sexual dimorphism. American Journal of Physical Anthropology, 137, pp. 324-333, 2008.

https://doi.org/10.1002/ajpa.20878

[2] Alvesalo, L., Human sex chromosomes in oral and craniofacial growth. Archives of Oral Biology, 54S, pp. 18-24, 2009.

https://doi.org/10.1016/j.archoralbio.2008.06.004

[3] Dempsey, P.J., Townsend, G.C. \& Richards, L.C. Increased tooth crown size in females with twin brothers: evidence for hormonal diffusion between human twins in utero. American Journal of Human Genetics, 11, pp. 577-586, 1999. https://doi.org/10.1002/(sici)1520-6300(199909/10)11:5<577::aid-ajhb1>3.3.co;2-p

[4] Ribeiro, D.C., Brook, A.H., Hughes, T.E., Sampson, W.J. \& Townsend, G.C., Intrauterine hormone effects on tooth dimensions. Journal of Dental Research, 92, pp. 425-431, 2013. https://doi.org/10.1177/0022034513484934

[5] Moorrees, C.F.A., Thomsen, S.O., Jensen, E. \& Yen, P.K., Mesiodistal crown diameters of the deciduous and permanent teeth in individuals. Journal of Dental Research, 36, pp. 39-47, 1957. https://doi.org/10.1177/00220345570360011501

[6] Ribeiro, D., Sampson, W., Hughes, T., Brook, A. \& Townsend, G., Sexual dimorphism in the primary and permanent dentitions of twins: an approach to clarifying the role of hormonal factors (Chapter 5). New Directions in Dental Anthropology: Paradigms, Methodologies and Outcomes, ed. G. Townsend, E. Kanazawa, H. Takayama, University of Adelaide Press: South Australia, pp. 46-64, 2012.

[7] Garn, S.M., Lewis, A.B., Swindler, D.R. \& Kerewsky, R.S., Genetic control of sexual dimorphism in tooth size. Journal of Dental Research, 46, pp. 963-972, 1967. https://doi.org/10.1177/00220345670460055801

[8] Acree, M.A., Is there a gender difference in fingerprint ridge density? Forensic Science International, 102, pp. 35-44, 1999. https://doi.org/10.1016/s0379-0738(99)00037-7

[9] Taduran, R.J.O., Tadeo, A.K.V., Escalona, N.A.C., \& Townsend, G.C., Sex determination from fingerprint ridge density and white line counts in Filipinos. HOMO - Journal of Comparative Human Biology, 67, pp. 163-171, 2016. https://doi.org/10.1016/j.jchb.2015.11.001

[10] Brook, A.H., Brook O’Donnell, M., Hone, A., Hart, E., Hughes, T.E., Smith, R.N. \& Townsend, G.C., General and craniofacial development are complex adaptive processes influenced by diversity. Australian Dental Journal, 59S, pp. 13-22, 2014. https://doi.org/10.1111/adj.12158

[11] Nanci, A., Ten Cate's oral histology: development, structure, and function, 7th edition, Elsevier Health Sciences: Missouri, pp. 16-107, 2008.

[12] Kücken, M. \& Newell, A.C., Fingerprint formation. Journal of Theoretical Biology, 235, pp. 71-83, 2005. https://doi.org/10.1016/j.jtbi.2004.12.020

[13] Taduran, R.J.O., Ranjitkar, S., Hughes, T., Townsend, G. \& Brook, A.H., Complex systems in human development: sexual dimorphism in teeth and fingerprints of Australian twins. International Journal of Design \& Nature and Ecodynamics, 11, pp. 676-685, 2016. https://doi.org/10.2495/dne-v11-n4-676-685 
[14] Townsend, G., Bockmann, M., Hughes, T., Mihailidis, S., Seow, K.W. \& Brook, A., New approaches to dental anthropology based on the study of twins (Chapter 2). New Directions in Dental Anthropology: Paradigms, Methodologies and Outcomes, ed. G. Townsend, E. Kanazawa, H. Takayama, University of Adelaide Press: South Australia, pp. 10-21, 2012.

[15] Hughes, T.E., Townsend, G.C., Pinkerton, S.K., Bockmann, M.R., Seow, W.K., Brook, A.H., Richards, L.C., Mihailidis, S., Ranjitkar, S. \& Lekkas, D., The teeth and faces of twins: providing insights into dentofacial development and oral health for practicing oral health professionals. Australian Dental Journal, 59S, pp. 101-116, 2014. https://doi.org/10.1111/adj.12101

[16] Brook, A.H., Griffin, R.C., Townsend, G., Levisianos, Y., Russell, J. \& Smith, R.N., Variability and patterning in permanent tooth size of four human ethnic groups. Archives of Oral Biology, 54S, pp. S79-S85, 2009.

https://doi.org/10.1016/j.archoralbio.2008.12.003

[17] Brook, A.H., Smith, R.N., Elcock, C., al-Sharood, M.H., Shah, A.A., Khalaf, F., Robinson, D.L., Lath, D.L. \& Karmo, M., The measurement of tooth morphology: validation of an image analysis system. 13th International Symposium of Dental Morphology. E. Zadzinska, University of Lodz Press: Lodz, pp. 475-482, 2005.

[18] Schneider, C.A., Rasband, W.S. \& Eliceiri, K.W., NIH Image to ImageJ: 25 years of image analysis. Nature Methods, 9, pp. 671-675, 2012.

https://doi.org/10.1038/nmeth.2089

[19] Mundorff, A.Z., Bartelink, E.J. \& Murad, T.A., Sexual dimorphism in finger ridge breadth measurements: a tool for sex estimation from fingerprints. Journal of Forensic Sciences, 59, pp. 891-897, 2014.

https://doi.org/10.1111/1556-4029.12449

[20] Ządzínska, E., Karasínska, M., Jedrychowska-Dánska, K., Watala, C. \& Witas, H.W., Sex diagnosis of subadult specimens from Medieval Polish archaeological sites: metric analysis of deciduous dentition. HOMO - Journal of Comparative Human Biology, 59, pp. $175-187,2008$.

https://doi.org/10.1016/j.jchb.2008.04.004

[21] Girija, K. \& Ambika, M., Permanent maxillary first molars: role in gender determination (morphometric analysis). Journal of Forensic Dental Sciences, 4, pp. 101-102, 2012.

[22] Griffin, J.E. \& Wilson, J.D., Disorders of the testes and the male reproductive tract (Chapter 18). Williams Textbook of Endocrinology, 10th edn., eds. P.R. Larsen, H.M. Kronemberg, S. Melmed \& K.S. Polonsky, W.B. Saunders Company: Philadelphia, pp. 709-770, 2003.

[23] Reyes, F.I., Boroditsky, R.S., Winter, J.S.D. \& Fairman, C., Studies on human sexual development. II. Fetal and maternal serum gonadotropin and sex steroid concentrations. Journal of Clinical Endocrinology and Metabolism, 38, pp. 612-617, 1974. https://doi.org/10.1210/jcem-38-4-612

[24] Knickmeyer, R.C. \& Baron-Cohen, S., Fetal testosterone and sex differences. Early Human Development, 82, pp. 755-760, 2006.

https://doi.org/10.1016/j.earlhumdev.2006.09.014

[25] AlQahtani, S.J., Hector, M.P. \& Liversidge, H.M., Brief communication: the London atlas of human tooth development and eruption. American Journal of Physical Anthropology, 142, pp. 481-490, 2010.

https://doi.org/10.1002/ajpa.21258 